\title{
Catalytic mechanism and bonding analyses of Au-Pd single atom alloy (SAA): CO oxidation reaction
}

\author{
Sambath Baskaran ${ }^{1,2}$, Cong-Qiao Xu ${ }^{2 *}$, Yang-Gang Wang ${ }^{2}$, Ignacio L. Garzón ${ }^{3}$ and Jun Li ${ }^{1,2^{*}}$
}

\begin{abstract}
Single-atom catalysts (SACs), including metalmetal-bonded bimetallic ones named single-atom alloys (SAAs), have aroused significant interest in catalysis. In this article, the catalytic mechanism and bonding analysis of $\mathrm{CO}$ oxidation reaction on bimetallic gold-palladium ( $\mathrm{Au}-\mathrm{Pd}$ ) model of single atom alloy $\mathrm{Au}_{37} \mathrm{Pd}_{1}$ are investigated by using quantum chemical calculations. The molecular geometries and adsorbate/substrate binding energies of $\mathrm{CO} @ \mathrm{Au}-\mathrm{Pd}$, $\mathrm{O}_{2} @ \mathrm{Au}-\mathrm{Pd}$ and $\mathrm{CO} / \mathrm{O}_{2} @ \mathrm{Au}-\mathrm{Pd}$ configurations are identified. The core-shell structure is confirmed to be the most stable structure for Au-Pd SAA, where the Pd atom prefers to situate at the core site. Charge transfer from the Pd atom to the $\mathrm{Au}$ atoms has been confirmed to stabilize the structure. According to the binding energy and chemical bonding analysis, both $\mathrm{CO}$ and $\mathrm{O}_{2}$ prefer to bind to the $\mathrm{Pd}$ atom at the hex site with low coordination number. The formation of new co-adsorption species is identified, in which vertical and parallel bridging adsorptions of $\mathrm{CO}$ and $\mathrm{O}_{2}$ on the $\mathrm{Au}-\mathrm{Pd}$ bonds are observed. $\mathrm{CO}$ oxidation on Au-Pd SAA is found to be feasible with low energy barriers and follows the Langmuir-Hinshewood (L-H) mechanism. Our work offers insights into the significant role of single atom of the SAAs in catalytic reactions and can provide evidence for designing new SAAs with high-performance catalytic activities.
\end{abstract}

Keywords: single-atom catalyst, $\mathrm{CO}$ oxidation, $\mathrm{Au}-\mathrm{Pd}$ alloy, bonding analysis, reaction mechanism

\section{INTRODUCTION}

Single-atom catalysts (SACs) have received much attention in recent years since it was first proposed in 2011 by Qiao and coworkers [1]. SACs have found significant applications in catalytic reactions such as $\mathrm{CO}$ oxidation
[1], water-gas shift (WGS) [2,3] and 1,3-butadiene hydrogenation reactions [4]. A huge number of reactions have been studied with SACs where single metal atoms anchored on oxide supports or metal surfaces act as the active sites [1,3,5-14]. Bimetallic nanoalloys have revealed superior catalytic activities and selectivities towards different catalytic reactions, when compared with monometallic nanoparticles (NPs) [13,15-26]. In this regard, great efforts have been devoted to the synthesis of nanosized bimetallic NPs with controllable particle size, structure and property. Previous studies reported that the structure, stability and activity of gold ( $\mathrm{Au}) \mathrm{NP}$ catalysts strongly depend on the size, shape and properties of the supports [27-39]. In recent years, gold based bimetallic nanoalloy catalysts were synthesized by introducing transition metals $(\mathrm{Pd}, \mathrm{Pt}$, Ir) to improve the catalytic efficiency [40-43]. Among them, gold-palladium (Au-Pd) bimetallic NPs were applied as potential catalysts in a wide range of catalytic reactions, such as oxidation of $\mathrm{CO}$ [43-45], hydrogen peroxide $\left(\mathrm{H}_{2} \mathrm{O}_{2}\right)$ synthesis from $\mathrm{H}_{2}$ and $\mathrm{O}_{2}$ [44,46-51], hydrocarbon and methanol oxidation [15,52-55], vinyl acetate (VA) synthesis [56,57], dehydration of formic acid [58], decomposition of $\mathrm{N}_{2} \mathrm{O}$ [13] and other transformations [59-64]. Pd-Cu single atom alloy (SAA) was found to be active for selective hydrogenation of styrene [65], acetylene [65], and phenylacetylene [66] by Flytzani-Stephanopoulos's group. Therefore, alloying the single palladium atom at gold clusters is an effective approach to investigate the functions of single Pd atom on the activity and selectivity of chemical reactions.

Several experimental studies were reported on $\mathrm{Au}-\mathrm{Pd}$ based bimetallic NP catalysts for $\mathrm{CO}$ oxidation reaction.

\footnotetext{
${ }^{1}$ Department of Chemistry and Key Laboratory of Organic Optoelectronics \& Molecular Engineering of Ministry of Education, Tsinghua University, Beijing 100084, China

2 Department of Chemistry, Southern University of Science and Technology, Shenzhen 518055, China

${ }^{3}$ Instituto de Física, Universidad Nacional Autónoma de México, CDMX, 04510, Mexico

* Corresponding authors (emails: xucq@sustech.edu.cn (Xu CQ); junli@tsinghua.edu.cn (Li J))
} 
Scott et al. [45] proposed that $\mathrm{TiO}_{2}$ supported $\mathrm{Au}-\mathrm{Pd}$ bimetallic catalysts prepared using dendrimer-encapsulated NPs show the utmost catalytic activity towards the $\mathrm{CO}$ oxidation compared with the supported $\mathrm{Au}$ and Pd monometallic catalysts. Yang and co-workers [67] reported the vapor phase synthesis and characterization of supported $\mathrm{Pd}, \mathrm{Au}$ and unsupported bimetallic NP catalysts for $\mathrm{CO}$ oxidation, where excellent activity of unsupported $\mathrm{Au}-\mathrm{Pd}$ bimetallic NPs for $\mathrm{CO}$ oxidation was observed. In 2010, Xu and co-workers [43] reported low temperature $\mathrm{CO}$ oxidation over $\mathrm{SiO}_{2}$ supported $\mathrm{Au}-\mathrm{Pd}$ bimetallic nanoalloy exhibiting remarkable activity. Gao et al. [68] also identified the superior activity of $\mathrm{TiO}_{2}$ supported $\mathrm{Au}-\mathrm{Pd}$ bimetallic nanoalloys for $\mathrm{CO}$ oxidation at low-temperature through reaction kinetics and spectroscopic investigations. Besides, numerous theoretical calculations were performed to study the properties and activities of Au-Pd bimetallic NPs in catalytic reactions. Density functional theory (DFT) studies on distributions of Pd atoms on Au NP by Yuan and co-workers [69] showed that $\mathrm{Pd}$ atoms might only prefer to locate at the face-centered cubic (fcc) (111) facets while leaving the fcc (100) facets for free. Structural rearrangement and catalytic performance are highly dependent on the reaction conditions such as gas molecule adsorptions. Previous DFT studies by Henkelman and co-workers [70] observed CO-adsorption-induced surface segregation of Pd on $\mathrm{Au} /$ Pd bimetallic surfaces. Our ab initio molecular dynamics (AIMD) simulations showed that the Pd atoms migrated from the core to the surface of the $\mathrm{Au}_{32} \mathrm{Pd}_{6}$ cluster with $\mathrm{H}_{2}$ adsorptions [71]. Zhu and co-workers [72] reported that Pd atoms would segregate and stabilize at edges of $\mathrm{Au}-\mathrm{Pd} \mathrm{NP}$ under $\mathrm{CO}$ exposure.

Although earlier studies found that the $\mathrm{Au}_{38} \mathrm{NP}$ with truncated octahedron (TO) was not the global minimum geometry [73,74], it was chosen as the theoretical model cluster to mimic the larger NPs, because this model owns all the vital sites and surfaces of the nanocrystal. Moreover, 38 is a magic number for the TO structure and this is the typical model for the large-size NPs [72,75-79]. Our group recently also investigated $\mathrm{Au}_{38}$ and $\mathrm{Au}-\mathrm{Ag}, \mathrm{Au}-\mathrm{Pd}$ bimetallic NPs exhibiting highly symmetric structure $\left(\mathrm{O}_{\mathrm{h}}\right)$, with all six $\mathrm{Ag}$ and $\mathrm{Pd}$ atoms located in the core site $[18,71,80]$. Thus we chose $\mathrm{Au}_{37} \mathrm{Pd}_{1}$ as a characteristic model to better understand the active site and catalytic mechanism of Au-Pd SAA. As the typical reaction mechanisms of $\mathrm{CO}$ oxidation have been well-established, investigations on the catalytic performance of $\mathrm{Au}_{37} \mathrm{Pd}_{1}$ SAA for CO oxidation can provide insights into the significant role of single atom on the catalytic activities. We examined the most stable structure, various adsorption patterns and reaction pathway for the selected $\mathrm{Au}-\mathrm{Pd}$ SAA through DFT calculations. Bonding analyses were also performed to better understand the electronic structure and the catalytic property. The findings here are helpful in predicting the structures and catalytic properties of other relevant SACs, SAAs, and even surface systems for related reactions.

\section{THEORETICAL METHODS}

Geometry optimizations and energy calculations were performed using spin-polarized DFT calculations as implemented in the Vienna ab initio simulation package (VASP) [81-83]. Projector augmented wave (PAW) method was employed to describe the interactions between the atomic cores and valence electrons [84]. The exchange-correlation energies were calculated via the generalized gradient approximation (GGA) with the Perdew-Burke-Ernzerhof (PBE) functional [85]. The valance electrons were described by $5 \mathrm{~d}^{10} 6 \mathrm{~s}^{1}$ for $\mathrm{Au}, 4 \mathrm{~d}^{9} 5 \mathrm{~s}^{1}$ for $\mathrm{Pd}, 2 \mathrm{~s}^{2} 2 \mathrm{p}^{4}$ for $\mathrm{O}$ and $2 \mathrm{~s}^{2} 2 \mathrm{p}^{2}$ for C. We used a $25 \AA \times 25 \AA \times 25 \AA$ cubic supercell for all the calculations, as reported by Lin et al. [86,87]. An energy cutoff of $400 \mathrm{eV}$ was chosen for the plane wave expansion of the electronic eigenfunctions. The Brillouin zone was sampled at the $\Gamma$ point. All the atoms were allowed to relax until the maximum force decreases below $0.03 \mathrm{eV} \AA^{-1}$. Atomic charge was calculated by Bader analysis $[88,89]$. The transition states (TSs) were determined using the dimer method [90-92]. Vibrational frequency calculations were performed to confirm that all stationary points were local minima (zero imaginary frequency) or TSs (one imaginary frequency).

The adsorption energy was calculated as $\Delta E_{\text {ads }}=E_{\text {total }}$ $-E_{\mathrm{Au}-\mathrm{Pd}}-E_{\text {adsorbate }}$, where $E_{\text {total }}, E_{\mathrm{Au}-\mathrm{Pd}}$ and $E_{\text {adsorbate }}$ are the energy of the $\mathrm{Au}-\mathrm{Pd}$ bimetallic NP with adsorbed gas species, bare $\mathrm{Au}-\mathrm{Pd}$ and free adsorbates, respectively. Furthermore, the co-adsorption energy of $\mathrm{CO}$ and $\mathrm{O}_{2}$ was defined as $\Delta E_{\text {coads }}=E_{\text {total }}-E_{\mathrm{Au}-\mathrm{Pd}}-E_{\mathrm{CO}}-E_{\mathrm{O} 2}$.

Energy decomposition analysis (EDA) was performed using DFT methods as implemented in the Amsterdam Density Functional (ADF 2016.101) program [93,94]. The PBE functional was used [85], together with the triplezeta plus polarization (TZP) Slater-type basis sets [95]. Frozen core approximations were applied to the inner shells $\left[1 s^{2}\right]$ for $\mathrm{C}$ and $\mathrm{O},\left[1 \mathrm{~s}^{2}-3 \mathrm{~d}^{10}\right]$ for $\mathrm{Pd}$ and $\left[1 \mathrm{~s}^{2}-4 \mathrm{~d}^{10}\right]$ for $\mathrm{Au}$. The scalar relativistic (SR) effects were taken into account by the zero-order-regular approximation (ZORA) $[96,97]$. To understand the bonding nature between $\mathrm{Au}-\mathrm{Pd} \mathrm{SAA}$ and the adsorbates, we performed 
natural bond orbital (NBO) analysis using NBO 6.0 package [98-100]. All-electron basis sets $6-311 \mathrm{G}^{*}[101]$ were used for $\mathrm{C}$ and $\mathrm{O}$ atoms. LANL2DZ $[102,103]$ basis sets and the corresponding effective core potentials (ECPs) were employed for $\mathrm{Au}$ and Pd atoms. These computational procedures were accomplished by using Gaussian 09 software package [104].

\section{RESULTS AND DISCUSSION}

Stability, geometry and bonding analysis of Au-Pd SAA Same as classified in our previous paper, three sites of the $\mathrm{NP}$ are defined as: core site at the core of the NP, cent site at the centroid of the fcc (111) facet and hex site at the (100) facet. Thus, as shown in Fig. S1, three isomers are found for gas phase $\mathrm{Au}_{37} \mathrm{Pd}_{1} \mathrm{SAA}$, where $\mathrm{Pd}$ atom locates at three distinct sites, respectively. $\mathrm{Au}-\mathrm{Pd}$ bond is stronger than $\mathrm{Au}-\mathrm{Au}$ bond [69] in the bimetallic NP because of its ionic feature. Consequently, the core structure is the most stable one, with the largest coordination number of $\mathrm{Pd}$ atom $\left(\mathrm{CN}_{\mathrm{Pd}}\right)$ in the core. The hex structure is the least stable isomer due to the weak $\mathrm{Au}-\mathrm{Pd}$ interactions caused by small $\mathrm{CN}_{\mathrm{Pd}}$. Our results reveal similar trend as Yuan and co-workers reported [69].

Various methods were applied to calculate the net charge of Pd atom in the Au-Pd isomers, as shown in Table S1. Mulliken charge could not describe this bimetallic NP system very well, which has been mentioned in other work [105]. All the other methods indicate that Pd is positively charged due to the stronger electronegativity of $\mathrm{Au}$ atom. The largest electron transfer from $\mathrm{Pd}$ to $\mathrm{Au}$ occurs in the core structure, further confirming its strong $\mathrm{Au}-\mathrm{Pd}$ interaction and stability. We compared average bond lengths and bond orders of $\mathrm{Au}-\mathrm{Pd}$ and $\mathrm{Au}_{\text {core }}{ }^{-}$ $\mathrm{Au}_{\text {core }}$ bonds in the core structure of $\mathrm{Au}-\mathrm{Pd} \mathrm{NP}$, as shown in Table S2. Bond lengths of $\mathrm{Au}-\mathrm{Pd}$ and $\mathrm{Au}-\mathrm{Au}$ are all larger than the sum of the corresponding Pyykkö covalent radii $\left(2.44 \AA, 2.48 \AA\right.$ ) [106]. $\mathrm{Au}_{\text {core }}-\mathrm{Pd}$ bond distance is smaller than $\mathrm{Au}_{\text {core }}-\mathrm{Au}_{\text {core }}$ as $\mathrm{Pd}$ atom presents smaller atomic radius. Besides, bond length and bond order of $\mathrm{Au}_{\text {hex }}-\mathrm{Pd}$ are both similar to that of $\mathrm{Au}_{\text {core }}-\mathrm{Pd}$ while $\mathrm{Au}_{\text {cent }}-\mathrm{Pd}$ shows apparent weak strength.

\section{Adsorption of Gas molecules}

To study the $\mathrm{CO}$ oxidation reaction on bimetallic $\mathrm{Au}-\mathrm{Pd}$ SAA, we first consider the stable adsorption structures of $\mathrm{CO}$ and $\mathrm{O}_{2}$ molecules on the Au-Pd SAA, as shown in Figs S2 and S3. As can be seen from Fig. S2, CO prefers to adsorb on the Au-Pd SAA by "end-on" configuration, where $\mathrm{C}$ atom binds to $\mathrm{Au}$ or Pd atom. Among all the optimized conformations, the most favorable $\mathrm{CO}$ adsorption structure is an "end-on" structure at the Pd site of the hex structure (STRA_1), with the adsorption energy of $-1.40 \mathrm{eV}$. The adsorption strength of $\mathrm{CO}$ is stronger at the $\mathrm{Pd}$ site than at the Au site. Compared with STRA_5 with CO adsorbed at the Au site, STRA_1 shows a shorter $\mathrm{Pd}-\mathrm{C}$ bond length $(1.91 \AA)$ and stronger adsorption energy of $0.54 \mathrm{eV}$. Pd and Au coordinated C-O bond is slightly elongated by about 0.02 and $0.01 \AA$ than free $\mathrm{CO}(\mathrm{C}-\mathrm{O}, 1.14 \AA$ ), respectively. Meanwhile, the $\mathrm{Pd}_{\text {cent }}$ site with larger CN of STRA_3 shows less favorable adsorption than $\mathrm{Pd}_{\text {hex }}$ site of STRA_1. These results suggest that the $\mathrm{CN}$ of $\mathrm{Pd}$ at the surface of the bimetallic nanoalloy has great influence on the $\mathrm{CO}$ adsorption. Previous studies by Zhu and co-workers [72] also demonstrated that $\mathrm{Pd}$ atoms would migrate toward the edge positions of bimetallic AuPd NPs in the presence of adsorbed CO.

In addition, we performed the Bader charge analysis for STRA_1 and STRA_5. The coordinated CO molecules are positively charged by $0.04|\mathrm{e}|$ for STRA_1 and negatively charged by $-0.03|\mathrm{e}|$ for STRA_5. The electron density difference (EDD) analysis shown in Fig. $1 \mathrm{a}$ and $\mathrm{b}$ indicates obvious charge transfer from the adsorption site of the SAA to CO molecule. To gain better understanding of the interaction between $\mathrm{CO}$ and $\mathrm{Au}-\mathrm{Pd} \mathrm{SAA}$, we carried out spin-polarized partial density of states (PDOS), as displayed in Fig. 1c and d. The Pd-4d orbitals strongly mix with $2 \pi^{*}$ orbitals of CO below the Fermi level (Fig. 1c) and there is no strong overlap between the Au-5d, 6s orbital with $2 \pi^{*}$ states of CO (Fig. 1d).

To investigate why $\mathrm{CO}$ adsorption is stronger at the $\mathrm{Pd}$ site than at the Au site, we performed the EDA for $\mathrm{CO}$ $+\mathrm{Au}-\mathrm{Pd} \rightarrow \mathrm{CO} @ \mathrm{Au}-\mathrm{Pd}$ process. The total energy shows that $\mathrm{CO}$ adsorption at the $\mathrm{Pd}$ site is $0.58 \mathrm{eV}$ lower in energy than at the Au site, consistent with the adsorption energy shown in Fig. S2. The steric interaction is the dominated term in the total energy and Pauli repulsion is the main component in the steric term (Table S3). Therefore, compared with Au site, $\mathrm{CO}$ adsorption at the $\mathrm{Pd}$ site with weaker electronegativity is more favorable because of easier electron transfer from Pd to $\mathrm{C}$ atom.

The Mayer bond orders and NBO population analysis of Pd-C and $\mathrm{Au}-\mathrm{C}$ bonds in STRA_1 and STRA_5 are listed in Table S4. It is found that $\mathrm{Pd}-\mathrm{C}$ bond order is larger than $\mathrm{Au}-\mathrm{C}$, indicating that $\mathrm{Pd}-\mathrm{C}$ bond is stronger than $\mathrm{Au}-\mathrm{C}$. The NBO population analysis shows that the major contributions of the $\mathrm{M}-\mathrm{C}$ bond are from $\mathrm{C}$ atom, illustrating a $\mathrm{OC} \rightarrow \mathrm{Pd}-\mathrm{Au}$ donation pattern. The s-d 

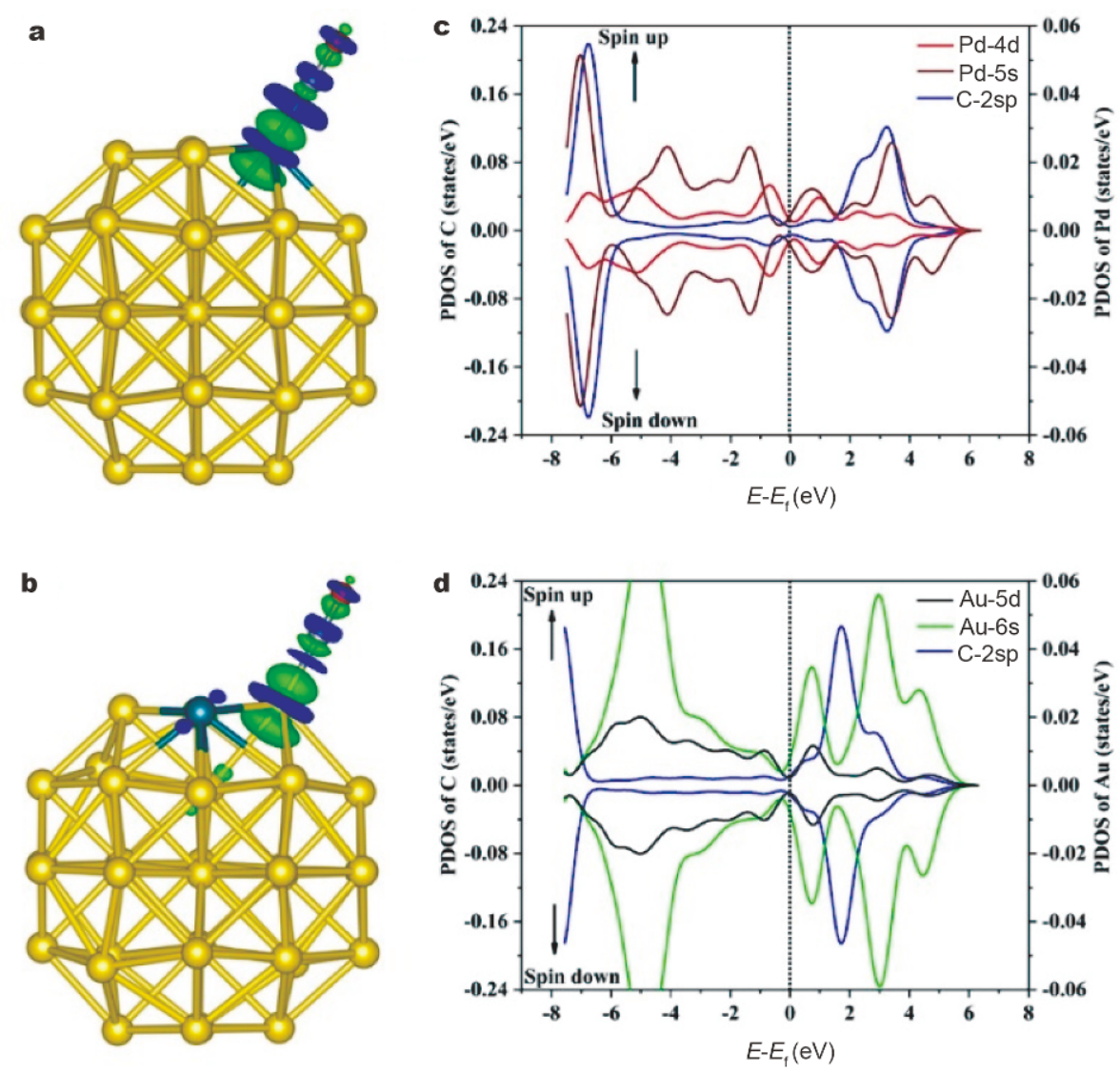

Figure 1 EDD for (a) STRA_1, (b) STRA_5 and the spin-polarized PDOS projected on (c) Pd-4d (red), Pd-5s (wine) and C-2sp (blue) for STRA_1, (d) Au-5d (black), Au-6s (green) and C-2sp (blue) states for STRA_5. For the contour plots, the charge accumulation regions are rendered in blue while the charge depletion regions are shown in green. The contour value of the electron difference density is 0.005 a.u. The Fermi level is set to zero, as shown by the dashed line.

hybridization of Pd and Au as well as the s-p hybridization of $\mathrm{C}$ is also clearly described. In Fig. S3, we can visualize the bonding orbitals of $\mathrm{Pd}-\mathrm{CO}$ and $\mathrm{Au}-\mathrm{CO}$, where the primary interactions result from overlaps of s-d hybridization of $\mathrm{M}$ and $5 \sigma$ orbital of $\mathrm{CO}$.

Various isomers of $\mathrm{O}_{2}$ adsorption on Au-Pd SAAs are shown in Fig. S4, which reveals that $\mathrm{O}_{2}$ can easily adsorb on two metal atoms of the SAA via the bridge binding mode. Unlike $\mathrm{CO}$ adsorption, "end-on" adsorption of $\mathrm{O}_{2}$ on Au-Pd SAA is difficult. The strongest $\mathrm{O}_{2}$ adsorption is observed in the hex Au-Pd structure (STRB_1) with the adsorption energy of $-0.84 \mathrm{eV}$, where two $\mathrm{O}$ atoms adsorb on the parallel bridging site of one $\mathrm{Au}-\mathrm{Pd}$ bond (i.e., side-on adsorption). The $\mathrm{O}-\mathrm{O}$ bond length of STRB_1 is $1.35 \AA$, much longer than that of the free $\mathrm{O}_{2}(1.23 \AA)$, indicating that $\mathrm{O}_{2}$ can be viewed as superoxide $\left(\mathrm{O}_{2}^{-}\right)$.

The Bader charge analysis suggests that $\mathrm{O}_{2}$ is negatively charged $(-0.32|\mathrm{e}|)$, while the connected $\mathrm{Pd}$ and $\mathrm{Au}$ atoms are positively charged $(0.33|\mathrm{e}|, 0.18|\mathrm{e}|)$. Therefore, $\mathrm{O}_{2}$ acts as the electron acceptor and $\mathrm{Au}-\mathrm{Pd} \mathrm{SAA}$ acts as the electron donor. The large amount of electron transfer to the partially occupied $2 \pi^{*}$ orbital of $\mathrm{O}_{2}$ leads to the elongation of the $\mathrm{O}-\mathrm{O}$ bond length. This result agrees well with the EDD analysis as shown in Fig. 2a, where the electron depletion region (green) is mainly localized around the $\mathrm{Pd}$ and $\mathrm{Au}$ atoms and the electron accumulation region (blue) around $\mathrm{O}_{2}$. Strong orbital overlaps are found between the $2 \pi^{*}$ orbital of $\mathrm{O}_{2}$ and $\mathrm{Pd}-4 \mathrm{~d}, \mathrm{Au}-5 \mathrm{~s}$, Au-5d orbitals in the PDOS graph (Fig. 2b).

In summary, $\mathrm{CO}$ and $\mathrm{O}_{2}$ both prefer to adsorb at the $\mathrm{Pd}$ site of the hex Au-Pd SAA because of its sufficient space for adsorbates and the weak interactions of the vertex atoms with the neighboring metal atoms. Easier charge transfer from $\mathrm{Pd}$ to $\mathrm{CO}$ or $\mathrm{O}_{2}$ also contributes to its stability. Besides, $\mathrm{O}_{2}$ adsorption is less favorable than $\mathrm{CO}$ adsorption on $\mathrm{Au}-\mathrm{Pd}$ SAA. 

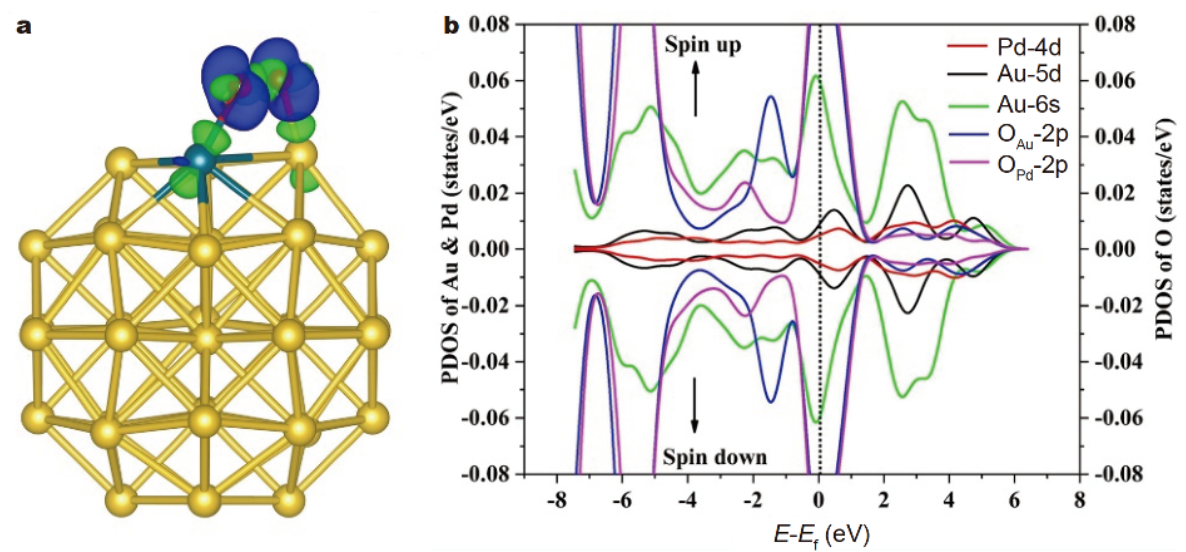

Figure 2 (a) EDD and (b) PDOS projected on Pd-4d (red), Au-5d (black), Au-6s (green), $\mathrm{O}_{\mathrm{Au}}-2 \mathrm{p}$ (blue) and $\mathrm{O}_{\mathrm{Pd}}-2 \mathrm{p}$ (magenta) states for STRB_1. For the contour plots, the charge accumulation regions are rendered in blue while the charge depletion regions are shown in green. The contour value of the electron difference density is 0.01 a.u. The Fermi level is set to zero, as shown by the dashed line.

\section{Co-adsorption of $\mathrm{CO}$ and $\mathrm{O}_{2}$ on bimetallic Au-Pd (hex) NPs}

In this section, co-adsorption of $\mathrm{CO}$ and $\mathrm{O}_{2}$ on the $\mathrm{Au}-\mathrm{Pd} \mathrm{SAA}$ is discussed to study the $\mathrm{CO}$ oxidation reactions. As shown in Fig. 3, several possible co-adsorption structures are considered and named as STRC_ $n(n=1-$ 7), respectively. The most beneficial co-adsorption configuration is STRC_1 $\left(\Delta E_{\text {ads }}=-1.94 \mathrm{eV}\right)$, in which the $\mathrm{O}_{2}$ molecule adsorbs on the parallel bridging site of the $\mathrm{Au}-\mathrm{Pd}$ bond and the $\mathrm{CO}$ molecule adsorbs on the vertical bridging site of the adjacent $\mathrm{Au}-\mathrm{Pd}$ bond. The bond lengths of the co-adsorbed $\mathrm{C}-\mathrm{O}$ and $\mathrm{O}-\mathrm{O}$ are 1.17 and $1.35 \AA$, respectively, similar to those of the single molecule adsorptions. As the adsorption strength of STRC_1 is stronger than STRA_1 and STRB_1, we can conclude that the co-adsorption structure is the most favorable intermediate in the reaction pathway.

\section{Reaction mechanism of CO oxidation on bimetallic Au-Pd NPs}

In general, $\mathrm{CO}$ oxidation reaction mainly proceeds via Langmuir-Hinshelwood (L-H), Eley-Rideal (E-R) or Mars-van Krevelen $(\mathrm{MvK})$ mechanism. As there is no surface lattice non-metal atom in the Au-Pd SAA, MvK mechanism is unlikely. For the E-R mechanism, the surface of Au-Pd SAA will be predominantly covered by $\mathrm{CO}$ molecule as the adsorption energy of $\mathrm{CO}(-1.40 \mathrm{eV})$ is much larger than $\mathrm{O}_{2}(-0.86 \mathrm{eV})$. Then the E- $\mathrm{R}$ mechanism that gaseous $\mathrm{O}_{2}$ adsorbs at the $\mathrm{CO}$ pre-adsorption configuration does not seem to be reasonable due to unfavored energetics. As $\mathrm{O}_{2}$ adsorption at the $\mathrm{Pd}$ atom with the pre-adsorbed $\mathrm{CO}$ is exothermic $(-0.54 \mathrm{eV})$, the $\mathrm{Pd}$ site will be covered by $\mathrm{CO}$ and $\mathrm{O}_{2}$ with the co-ad- sorption structure instantly under $\mathrm{CO}$ oxidation conditions. Accordingly, we focus on the well-accepted L-H mechanism in this article.

For the L-H mechanism, the structures of intermediates (IMs), TSs and the potential energy profile for $\mathrm{CO}$ oxidation reaction are summarized in Figs 4 and 5. As coadsorption is the strongest adsorption pattern, we take STRC_1 as the initial configuration for the further CO oxidation reactions. Then the adsorbed $\mathrm{O}_{2}$ molecule interacts with the adsorbed $\mathrm{CO}$ to yield peroxo-type (OOCO) complex intermediate (IM2) through an energy barrier of $0.73 \mathrm{eV}$. Afterwards, the cleavage of $\mathrm{O}-\mathrm{O}$ bond of OOCO intermediate occurs immediately, resulting in the subsequent elimination of a $\mathrm{CO}_{2}$ molecule and an oxygen atom on the Au-Pd SAA. Then a new CO molecule adsorbs on the $\mathrm{Pd}$ site and reacts with the remaining $\mathrm{O}$ atom, forming another $\mathrm{CO}_{2}$ molecule with an energy barrier of $0.84 \mathrm{eV}$. All fundamental steps of the catalytic cycle are exothermic and the energy barriers for the TSs (TS1 and TS2) are reasonable for the CO oxidation reaction under ambient experimental conditions.

We used Bader charges (see Table 1), EDD and PDOS to further analyze the electronic structures of the $\mathrm{Au}-\mathrm{Pd}$ SAA during the $\mathrm{CO}$ oxidation reaction. It can be seen from the co-adsorption superoxo structure IM1 that there is obvious charge transfer from Au-Pd SAA to the adsorbates, where the Bader charges of the adsorbed $\mathrm{O}_{2}$ and CO molecules are $-0.63|\mathrm{e}|$ and $-0.19|\mathrm{e}|$, respectively. This result reveals that there are more charge transfers from the SAA to $\mathrm{O}_{2}$ adsorption and the Bader charge of the SAA increases significantly to $0.82|\mathrm{e}|$. The charge transfer is also observed in the EDD analysis shown in Fig. S5a, where obvious electron accumulations at $2 \pi^{*}$ orbitals of 

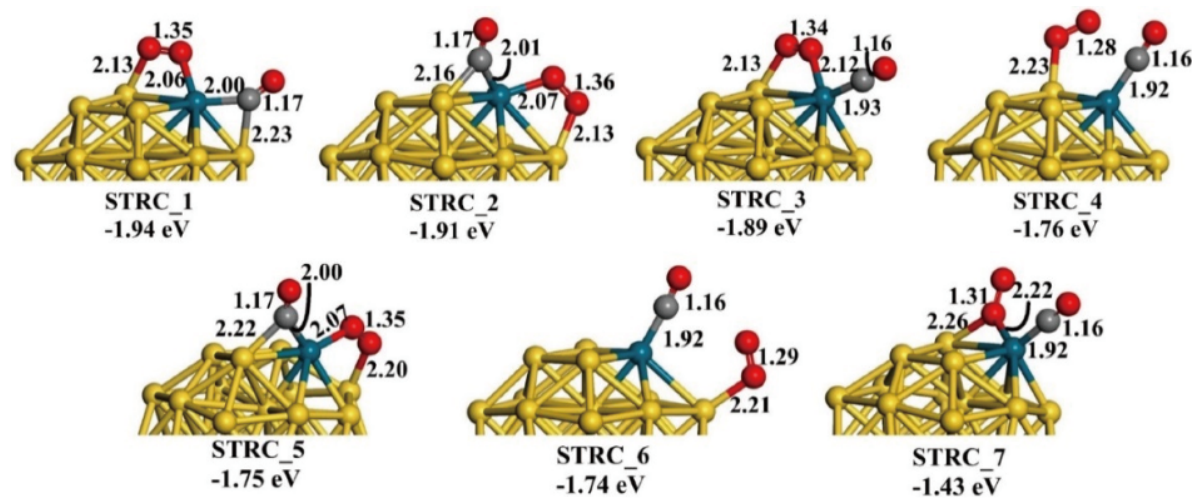

Figure 3 Co-adsorption structures and adsorption energies of $\mathrm{CO}$ and $\mathrm{O}_{2}$ on $\mathrm{Au}-\mathrm{Pd}$ bimetallic NPs. Selected bond lengths are marked in $\AA$.

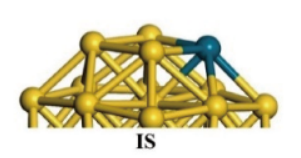

IS

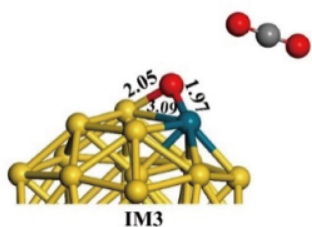

IM3

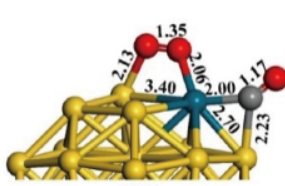

IM1

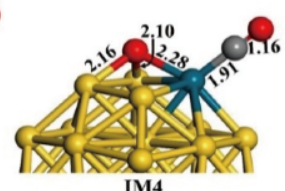

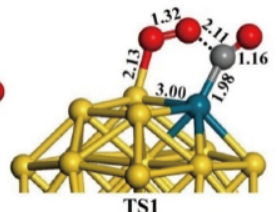

TS1

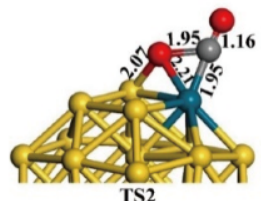

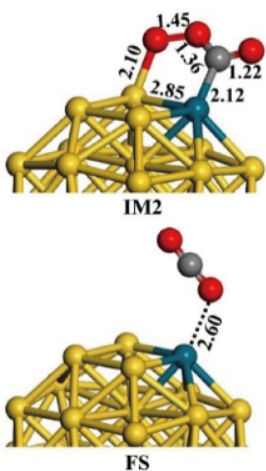

FS

Figure 4 The structures of initial state (IS), TSs, IMs and final state (FS) in CO oxidation reaction on Au-Pd SAA. Selected bond lengths are marked in $\AA$.

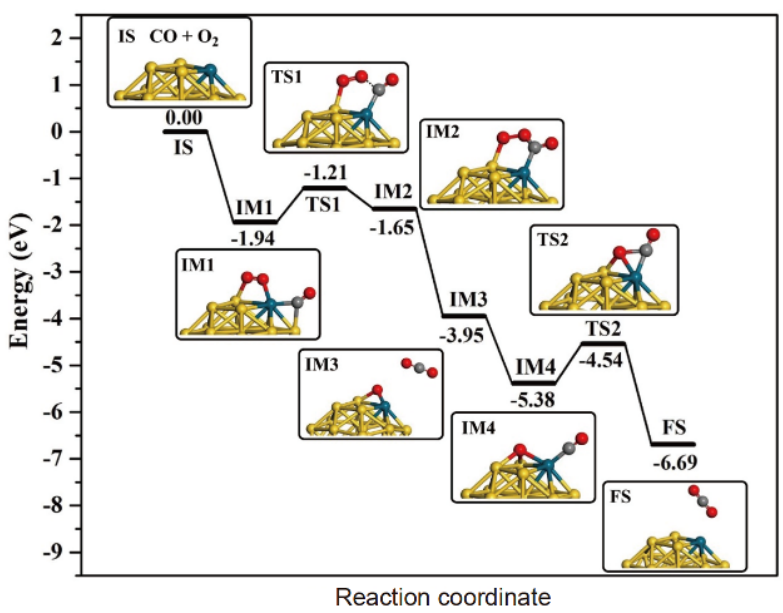

Figure 5 Schematic potential energy profile for the CO oxidation reaction on Au-Pd SAA via the L-H mechanism. IM1 and IM2 feature activated superoxo and peroxo $\mathrm{O}_{2}$ species, respectively.

$\mathrm{O}_{2}$ and $\mathrm{CO}$ molecules mainly contribute to the enlarged $\mathrm{O}-\mathrm{O}$ and $\mathrm{C}-\mathrm{O}$ bond lengths. Besides, strong interactions between $\mathrm{CO}, \mathrm{O}_{2}$ and SAA are shown in PDOS (see Fig. S5b and c), with apparent $2 \pi^{*}\left(\mathrm{O}_{2}\right)$ orbitals located near the Fermi level and partially occupied $2 \pi^{*}$ orbitals of CO.

When one $\mathrm{O}$ atom of the $\mathrm{O}_{2}$ molecule approaches to the $\mathrm{CO}$ molecule to form TS1, less charge transfers from SAA to the adsorbates and apparent charge transfer from $\mathrm{CO}$ to $\mathrm{O}_{2}$ molecule is observed, as shown in Table 1 and Fig. S6a. PDOS in Fig. S6b also reveals that the $\mathrm{O}$ atom dissociated from $\mathrm{O}_{2}$ interacts with $\mathrm{CO}$ and contributes to remarkably enhanced C-2sp distributions below the Fermi level. After the formation of the first $\mathrm{CO}_{2}$ molecule, a negatively charged $\mathrm{O}^{x-}(x=1,2)$ ion is left on the SAA, resulting in an increase of the positive charge of the SAA in IM3. Then the adsorption of the second CO molecule at the Pd site causes more charges transfer from the SAA. Finally, charge transfers back to the SAA with the release of the second $\mathrm{CO}_{2}$ molecule.

\section{CONCLUSIONS}

In the present study, we have probed the catalytic me- 
Table 1 Bader charges of IS, IMs, TSs and FS in the reaction pathway ${ }^{\mathrm{a}}$

\begin{tabular}{|c|c|c|c|c|c|c|c|c|}
\hline Systems & {$[\mathrm{Pd}]$} & [Au-Pd] & [CO_1] & {$\left[\mathrm{O}_{2}\right]$} & [OOCO] & [CO_2] & {$[\mathrm{O}]$} & [OCO] \\
\hline STRA_1 & 0.23 & 0.16 & -0.16 & - & - & - & - & - \\
\hline IM1 & 0.43 & 0.82 & -0.19 & -0.63 & -0.82 & - & - & - \\
\hline TS1 & 0.22 & 0.58 & -0.09 & -0.49 & -0.58 & - & - & - \\
\hline IM2 & 0.24 & 0.67 & 0.75 & -1.42 & -0.67 & - & - & - \\
\hline IM3 & 0.37 & 0.79 & - & - & - & - & -0.79 & - \\
\hline IM4 & 0.40 & 0.97 & - & - & - & -0.16 & -0.81 & -0.97 \\
\hline TS2 & 0.39 & 0.78 & - & - & - & -0.03 & -0.76 & -0.79 \\
\hline FS & 0.13 & 0.00 & - & - & - & - & - & - \\
\hline
\end{tabular}

a) $[\mathrm{Pd}]$ and $[\mathrm{Au}-\mathrm{Pd}]$ refer to the charge of the Pd atom and total charge of Au-Pd SAA, [CO_1], [CO_2] and $\left[\mathrm{O}_{2}\right]$ refer to the charge of the first, second adsorbed $\mathrm{CO}$ and $\mathrm{O}_{2}$ molecules, while [OOCO], $[\mathrm{O}]$ and [OCO] refer to the charges of the adsorbates at the surfaces SAA.

chanism of $\mathrm{CO}$ oxidation reaction on $\mathrm{Au}-\mathrm{Pd}$ single atom alloy $\mathrm{Au}_{37} \mathrm{Pd}_{1}$ via $\mathrm{DFT}$ calculations. The relative energies and electronic structures of Au-Pd SAAs reveal that Pd atom at the core site is more favored than the cent and hex sites. CO prefers terminal adsorption at the Pd site of $\mathrm{Au}-\mathrm{Pd} \mathrm{SAA}$ while $\mathrm{O}_{2}$ tends to form a bridging bond with $\mathrm{Pd}$ and its adjacent $\mathrm{Au}$ atom. The co-adsorption structure of $\mathrm{CO} / \mathrm{O}_{2} @ \mathrm{Au}-\mathrm{Pd}$ is found to be the most beneficial adsorption configuration, where $\mathrm{CO}$ and $\mathrm{O}_{2}$ molecules adsorb on the vertical (end-on) and parallel bridging (side-on) sites of Au-Pd bonds, respectively. The calculated energy profile indicates that $\mathrm{CO}$ oxidation reaction on $\mathrm{Au}-\mathrm{Pd}$ SAA follows the L-H mechanism and is feasible at relatively low temperature due to the low activation energy barriers $(0.73$ and $0.84 \mathrm{eV})$. This work yields guidelines for understanding the active sites and catalytic mechanisms of $\mathrm{Au}-\mathrm{Pd} \mathrm{NPs}$, which may also provide evidence for designing new SAAs with high-performance catalytic activities.

Received 11 December 2019; accepted 17 January 2020; published online 9 March 2020

1 Qiao B, Wang A, Yang X, et al. Single-atom catalysis of CO oxidation using $\mathrm{Pt}_{1} / \mathrm{FeO}_{x}$. Nat Chem, 2011, 3: 634-641

2 Fu Q, Saltsburg H, Flytzani-Stephanopoulos M. Active nonmetallic Au and Pt species on ceria-based water-gas shift catalysts. Science, 2003, 301: 935-938

3 Yang M, Allard LF, Flytzani-Stephanopoulos M. Atomically dispersed $\mathrm{Au}-(\mathrm{OH})_{x}$ species bound on titania catalyze the lowtemperature water-gas shift reaction. J Am Chem Soc, 2013, 135: 3768-3771

4 Zhang X, Shi H, Xu BQ. Catalysis by gold: Isolated surface $\mathrm{Au}^{3+}$ ions are active sites for selective hydrogenation of 1,3-butadiene over $\mathrm{Au} / \mathrm{ZrO}_{2}$ catalysts. Angew Chem Int Ed, 2005, 44: 7132-7135

5 Chen $\mathrm{F}, \mathrm{Li} \mathrm{T}$, Pan $\mathrm{X}$, et al. $\mathrm{Pd}_{1} / \mathrm{CeO}_{2}$ single-atom catalyst for alkoxycarbonylation of aryl iodides. Sci China Mater, 2020, https://doi.org/10.1007/s40843-019-1204-y

6 Flytzani-Stephanopoulos M, Gates BC. Atomically dispersed supported metal catalysts. Annu Rev Chem Biomol Eng, 2012, 3: 545-574

7 Liang JX, Wang YG, Xing DH, et al. Recent advances in singleatom catalysis. Encycl Inorg Bioinorg Chem, 2017, 1-11

8 Lin J, Wang A, Qiao B, et al. Remarkable performance of $\mathrm{Ir}_{1} / \mathrm{FeO}_{x}$ single-atom catalyst in water gas shift reaction. J Am Chem Soc, 2013, 135: 15314-15317

9 Lin J, Wang X. Rh single atom catalyst for direct conversion of methane to oxygenates. Sci China Mater, 2018, 61: 758-760

10 Liu JC, Tang Y, Wang YG, et al. Theoretical understanding of the stability of single-atom catalysts. Natl Sci Rev, 2018, 5: 638-641

11 Thomas JM, Saghi Z, Gai PL. Can a single atom serve as the active site in some heterogeneous catalysts? Top Catal, 2011, 54: 588594

12 Wang A, Li J, Zhang T. Heterogeneous single-atom catalysis. Nat Rev Chem, 2018, 2: 65-81

13 Wei X, Yang XF, Wang AQ, et al. Bimetallic Au-Pd alloy catalysts for $\mathrm{N}_{2} \mathrm{O}$ decomposition: Effects of surface structures on catalytic activity. J Phys Chem C, 2012, 116: 6222-6232

14 Yang XF, Wang A, Qiao B, et al. Single-atom catalysts: A new frontier in heterogeneous catalysis. Acc Chem Res, 2013, 46: $1740-1748$

15 Chang CR, Long B, Yang XF, et al. Theoretical studies on the synergetic effects of Au-Pd bimetallic catalysts in the selective oxidation of methanol. J Phys Chem C, 2015, 119: 16072-16081

16 Ferrando R, Jellinek J, Johnston RL. Nanoalloys: From theory to applications of alloy clusters and nanoparticles. Chem Rev, 2008, 108: 845-910

17 Kim D, Resasco J, Yu Y, et al. Synergistic geometric and electronic effects for electrochemical reduction of carbon dioxide using gold-copper bimetallic nanoparticles. Nat Commun, 2014, 5: 4948

18 Liu X, Wang A, Yang X, et al. Synthesis of thermally stable and highly active bimetallic $\mathrm{Au}-\mathrm{Ag}$ nanoparticles on inert supports. Chem Mater, 2009, 21: 410-418

19 Ma XL, Liu JC, Xiao H, et al. Surface single-cluster catalyst for $\mathrm{N}_{2}-$ to- $\mathrm{NH}_{3}$ thermal conversion. J Am Chem Soc, 2018, 140: 46-49

20 Nakamula I, Yamanoi Y, Imaoka T, et al. A uniform bimetallic rhodium/iron nanoparticle catalyst for the hydrogenation of olefins and nitroarenes. Angew Chem Int Ed, 2011, 50: 58305833

21 Rong H, Niu Z, Zhao Y, et al. Structure evolution and associated catalytic properties of Pt-Sn bimetallic nanoparticles. Chem Eur J, 
2015, 21: 12034-12041

22 Shibata T, Bunker BA, Zhang Z, et al. Size-dependent spontaneous alloying of $\mathrm{Au}-\mathrm{Ag}$ nanoparticles. J Am Chem Soc, 2002, 124: $11989-11996$

23 Xie S, Tsunoyama H, Kurashige W, et al. Enhancement in aerobic alcohol oxidation catalysis of $\mathrm{Au}_{25}$ clusters by single $\mathrm{Pd}$ atom doping. ACS Catal, 2012, 2: 1519-1523

24 Zhang S, Nguyen L, Liang JX, et al. Catalysis on singly dispersed bimetallic sites. Nat Commun, 2015, 6: 7938

25 Zhou H, Yang X, Li L, et al. PdZn intermetallic nanostructure with $\mathrm{Pd}-\mathrm{Zn}-\mathrm{Pd}$ ensembles for highly active and chemoselective semi-hydrogenation of acetylene. ACS Catal, 2016, 6: 1054-1061

26 Zhu W, Shan J, Nguyen L, et al. Evolution of surface of Pd-Rh bimetallic nanocubes and its correlation with $\mathrm{CO}$ oxidation. Sci China Mater, 2019, 62: 103-114

27 Carrettin S, Concepción P, Corma A, et al. Nanocrystalline $\mathrm{CeO}_{2}$ increases the activity of $\mathrm{Au}$ for $\mathrm{CO}$ oxidation by two orders of magnitude. Angew Chem Int Ed, 2004, 43: 2538-2540

28 Chen MS, Goodman DW. Structure-activity relationships in supported Au catalysts. Catal Today, 2006, 111: 22-33

29 Gluhoi AC, Dekkers MAP, Nieuwenhuys BE. Comparative studies of the $\mathrm{N}_{2} \mathrm{O} / \mathrm{H}_{2}, \mathrm{~N}_{2} \mathrm{O} / \mathrm{CO}, \mathrm{H}_{2} / \mathrm{O}_{2}$ and $\mathrm{CO} / \mathrm{O}_{2}$ reactions on supported gold catalysts: Effect of the addition of various oxides. J Catal, 2003, 219: 197-205

30 Grisel RJH, Nieuwenhuys BE. Selective oxidation of CO, over supported Au catalysts. J Catal, 2001, 199: 48-59

31 Haruta M. Size- and support-dependency in the catalysis of gold. Catal Today, 1997, 36: 153-166

32 Haruta M, Tsubota S, Kobayashi T, et al. Low-temperature oxidation of $\mathrm{CO}$ over gold supported on $\mathrm{TiO}_{2}, \alpha-\mathrm{Fe}_{2} \mathrm{O}_{3}$, and $\mathrm{Co}_{3} \mathrm{O}_{4}$. J Catal, 1993, 144: 175-192

33 Liu W, Liu Z, Wang G, et al. Carbon coated $\mathrm{Au} / \mathrm{TiO}_{2}$ mesoporous microspheres: A novel selective photocatalyst. Sci China Mater, 2017, 60: 438-448

34 Matthey D, Wang JG, Wendt S, et al. Enhanced bonding of gold nanoparticles on oxidized $\mathrm{TiO}_{2}(110)$. Science, 2007, 315: 16921696

35 Molina LM, Hammer B. Active role of oxide support during CO oxidation at Au/MgO. Phys Rev Lett, 2003, 90: 206102

36 Mpourmpakis G, Caratzoulas S, Vlachos DG. What controls Au nanoparticle dispersity during growth? Nano Lett, 2010, 10: 3408-3413

37 Romero-Sarria F, Martínez T LM, Centeno MA, et al. Surface dynamics of $\mathrm{Au} / \mathrm{CeO}_{2}$ catalysts during $\mathrm{CO}$ oxidation. J Phys Chem C, 2007, 111: 14469-14475

38 Sanchez A, Abbet S, Heiz U, et al. When gold is not noble: Nanoscale gold catalysts. J Phys Chem A, 1999, 103: 9573-9578

39 Schubert MM, Hackenberg S, van Veen AC, et al. CO oxidation over supported gold catalysts- "inert" and "active" support materials and their role for the oxygen supply during reaction. J Catal, 2001, 197: 113-122

40 Bokhimi X, Zanella R, Angeles-Chavez C. Rutile-supported Ir, $\mathrm{Au}$, and $\mathrm{Ir}-\mathrm{Au}$ catalysts for CO oxidation. J Phys Chem C, 2010, 114: 14101-14109

41 Gao Y, Shao N, Pei Y, et al. Icosahedral crown gold nanocluster $\mathrm{Au}_{43} \mathrm{Cu}_{12}$ with high catalytic activity. Nano Lett, 2010, 10: 10551062

42 Luo Y, Seo HO, Kim KD, et al. CO oxidation of $\mathrm{Au}-\mathrm{Pt}$ nanostructures: Enhancement of catalytic activity of Pt nanoparticles by Au. Catal Lett, 2010, 134: 45-50
43 Xu J, White T, Li P, et al. Biphasic Pd-Au alloy catalyst for lowtemperature CO oxidation. J Am Chem Soc, 2010, 132: 1039810406

44 Hutchings GJ. Nanocrystalline gold and gold palladium alloy catalysts for chemical synthesis. Chem Commun, 2008, 10: 11481164

45 Scott RWJ, Sivadinarayana C, Wilson OM, et al. Titania-supported PdAu bimetallic catalysts prepared from dendrimer-encapsulated nanoparticle precursors. J Am Chem Soc, 2005, 127: $1380-1381$

46 Abate S, Centi G, Melada S, et al. Preparation, performances and reaction mechanism for the synthesis of $\mathrm{H}_{2} \mathrm{O}_{2}$ from $\mathrm{H}_{2}$ and $\mathrm{O}_{2}$ based on palladium membranes. Catal Today, 2005, 104: 323-328

47 Beletskaya AV, Pichugina DA, Shestakov AF, et al. Formation of $\mathrm{H}_{2} \mathrm{O}_{2}$ on $\mathrm{Au}_{20}$ and $\mathrm{Au}_{19} \mathrm{Pd}$ clusters: Understanding the structure effect on the atomic level. J Phys Chem A, 2013, 117: 6817-6826

48 Edwards JK, Carley AF, Herzing AA, et al. Direct synthesis of hydrogen peroxide from $\mathrm{H}_{2}$ and $\mathrm{O}_{2}$ using supported $\mathrm{Au}-\mathrm{Pd}$ catalysts. Faraday Discuss, 2008, 138: 225-239

49 Edwards J, Solsona B, Landon P, et al. Direct synthesis of hydrogen peroxide from $\mathrm{H}_{2}$ and $\mathrm{O}_{2}$ using $\mathrm{TiO}_{2}$-supported $\mathrm{Au}-\mathrm{Pd}$ catalysts. J Catal, 2005, 236: 69-79

50 Ham HC, Hwang GS, Han J, et al. On the role of Pd ensembles in selective $\mathrm{H}_{2} \mathrm{O}_{2}$ formation on PdAu alloys. J Phys Chem C, 2009, 113: 12943-12945

51 Samanta C. Direct synthesis of hydrogen peroxide from hydrogen and oxygen: An overview of recent developments in the process. Appl Catal A-General, 2008, 350: 133-149

52 Jover J, García-Ratés M, López N. The interplay between homogeneous and heterogeneous phases of PdAu catalysts for the oxidation of alcohols. ACS Catal, 2016, 6: 4135-4143

53 Ab Rahim MH, Forde MM, Jenkins RL, et al. Oxidation of methane to methanol with hydrogen peroxide using supported goldpalladium alloy nanoparticles. Angew Chem Int Ed, 2013, 52: $1280-1284$

54 Enache DI, Edwards JK, Landon P, et al. Solvent-free oxidation of primary alcohols to aldehydes using $\mathrm{Au}-\mathrm{Pd} / \mathrm{TiO}_{2}$ catalysts. Science, 2006, 311: 362-365

55 Kesavan L, Tiruvalam R, Ab Rahim MH, et al. Solvent-free oxidation of primary carbon-hydrogen bonds in toluene using AuPd alloy nanoparticles. Science, 2011, 331: 195-199

56 Han Y, Wang J, Kumar D, et al. A kinetic study of vinyl acetate synthesis over Pd-based catalysts: Kinetics of vinyl acetate synthesis over $\mathrm{Pd}-\mathrm{Au} / \mathrm{SiO}_{2}$ and $\mathrm{Pd} / \mathrm{SiO}_{2}$ catalysts. J Catal, 2005, 232: $467-475$

57 Chen M, Kumar D, Yi CW, et al. The promotional effect of gold in catalysis by palladium-gold. Science, 2005, 310: 291-293

$58 \mathrm{Gu} \mathrm{X}, \mathrm{Lu} \mathrm{ZH}$, Jiang HL, et al. Synergistic catalysis of metalorganic framework-immobilized Au-Pd nanoparticles in dehydrogenation of formic acid for chemical hydrogen storage. J Am Chem Soc, 2011, 133: 11822-11825

59 Allison EG, Bond GC. The structure and catalytic properties of palladium-silver and palladium-gold alloys. Catal Rev, 1972, 7: 233-289

60 Nutt MO, Hughes JB, Michael SW. Designing Pd-on-Au bimetallic nanoparticle catalysts for trichloroethene hydrodechlorination. Environ Sci Technol, 2005, 39: 1346-1353

61 Venezia AM, La Parola V, Nicolı V, et al. Effect of gold on the HDS activity of supported palladium catalysts. J Catal, 2002, 212: $56-62$ 
62 Lee AF, Baddeley CJ, Hardacre C, et al. Structural and catalytic properties of novel $\mathrm{Au} / \mathrm{Pd}$ bimetallic colloid particles: EXAFS, XRD, and acetylene coupling. J Phys Chem, 1995, 99: 6096-6102

63 Kaiser J, Leppert L, Welz H, et al. Catalytic activity of nanoalloys from gold and palladium. Phys Chem Chem Phys, 2012, 14: 6487-6495

64 Turkenburg DH, Antipov AA, Thathagar MB, et al. Palladium nanoclusters in microcapsule membranes: From synthetic shells to synthetic cells. Phys Chem Chem Phys, 2005, 7: 2237-2240

65 Kyriakou G, Boucher MB, Jewell AD, et al. Isolated metal atom geometries as a strategy for selective heterogeneous hydrogenations. Science, 2012, 335: 1209-1212

66 Boucher MB, Zugic B, Cladaras G, et al. Single atom alloy surface analogs in $\mathrm{Pd}_{0.18} \mathrm{Cu}_{15}$ nanoparticles for selective hydrogenation reactions. Phys Chem Chem Phys, 2013, 15: 12187-12196

67 Yang Y, Saoud KM, Abdelsayed V, et al. Vapor phase synthesis of supported $\mathrm{Pd}, \mathrm{Au}$, and unsupported bimetallic nanoparticle catalysts for CO oxidation. Catal Commun, 2006, 7: 281-284

68 Gao F, Wang Y, Goodman DW. Reaction kinetics and polarization-modulation infrared reflection absorption spectroscopy (PM-IRAS) investigation of $\mathrm{CO}$ oxidation over supported $\mathrm{Pd}-\mathrm{Au}$ alloy catalysts. J Phys Chem C, 2010, 114: 4036-4043

69 Yuan D, Gong X, Wu R. Peculiar distribution of Pd on Au nanoclusters: First-principles studies. Phys Rev B, 2008, 78: 035441

70 Kim HY, Henkelman G. CO adsorption-driven surface segregation of Pd on Au/Pd bimetallic surfaces: Role of defects and effect on CO oxidation. ACS Catal, 2013, 3: 2541-2546

71 Xu CQ, Lee MS, Wang YG, et al. Structural rearrangement of $\mathrm{Au}-\mathrm{Pd}$ nanoparticles under reaction conditions: An ab initio molecular dynamics study. ACS Nano, 2017, 11: 1649-1658

72 Zhu B, Thrimurthulu G, Delannoy L, et al. Evidence of Pd segregation and stabilization at edges of AuPd nano-clusters in the presence of CO: A combined DFT and DRIFTS study. J Catal, 2013, 308: 272-281

73 Jiang D, Walter M. $\mathrm{Au}_{40}$ : A large tetrahedral magic cluster. Phys Rev B, 2011, 84: 193402

74 Garzón IL, Michaelian K, Beltrán MR, et al. Lowest energy structures of gold nanoclusters. Phys Rev Lett, 1998, 81: 16001603

75 Ismail R, Johnston RL. Investigation of the structures and chemical ordering of small Pd-Au clusters as a function of composition and potential parameterisation. Phys Chem Chem Phys, 2010, 12: 8607-8619

76 Paz-Borbón LO, Johnston RL, Barcaro G, et al. Structural motifs, mixing, and segregation effects in 38-atom binary clusters. J Chem Phys, 2008, 128: 134517

77 Pittaway F, Paz-Borbón LO, Johnston RL, et al. Theoretical studies of palladium-gold nanoclusters: $\mathrm{Pd}-\mathrm{Au}$ clusters with up to 50 atoms. J Phys Chem C, 2009, 113: 9141-9152

78 Roldán A, Ricart JM, Illas F. Influence of the exchange-correlation potential on the description of the molecular mechanism of oxygen dissociation by Au nanoparticles. Theor Chem Acc, 2009, 123: $119-126$

79 West PS, Johnston RL, Barcaro G, et al. The effect of CO and H chemisorption on the chemical ordering of bimetallic clusters. J Phys Chem C, 2010, 114: 19678-19686

80 Chang CR, Huang ZQ, Li J. Hydrogenation of molecular oxygen to hydroperoxyl: An alternative pathway for $\mathrm{O}_{2}$ activation on nanogold catalysts. Nano Res, 2015, 8: 3737-3748

81 Kresse G, Furthmüller J. Efficiency of ab-initio total energy cal- culations for metals and semiconductors using a plane-wave basis set. Comput Mater Sci, 1996, 6: 15-50

82 Kresse G, Hafner J. Ab initio molecular dynamics for liquid metals. Phys Rev B, 1993, 47: 558-561

83 Kresse G, Hafner J. Ab initio molecular-dynamics simulation of the liquid-metal-amorphous-semiconductor transition in germanium. Phys Rev B, 1994, 49: 14251-14269

84 Blöchl PE. Projector augmented-wave method. Phys Rev B, 1994, 50: $17953-17979$

85 Perdew JP, Burke K, Ernzerhof M. Generalized gradient approximation made simple. Phys Rev Lett, 1996, 77: 3865-3868

86 Lin RJ, Chen HL, Ju SP, et al. Quantum-chemical calculations on the mechanism of the water-gas shift reaction on nanosized gold cluster. J Phys Chem C, 2012, 116: 336-342

87 Wu SK, Lin RJ, Jang S, et al. Theoretical investigation of the mechanism of the water-gas shift reaction on cobalt@gold coreshell nanocluster. J Phys Chem C, 2014, 118: 298-309

88 Tang W, Sanville E, Henkelman G. A grid-based bader analysis algorithm without lattice bias. J Phys-Condens Matter, 2009, 21: 084204

89 Yu M, Trinkle DR. Accurate and efficient algorithm for bader charge integration. J Chem Phys, 2011, 134: 064111

90 Henkelman G, Jónsson H. A dimer method for finding saddle points on high dimensional potential surfaces using only first derivatives. J Chem Phys, 1999, 111: 7010-7022

91 Heyden A, Bell AT, Keil FJ. Efficient methods for finding transition states in chemical reactions: Comparison of improved dimer method and partitioned rational function optimization method. J Chem Phys, 2005, 123: 224101

92 Kästner J, Sherwood P. Superlinearly converging dimer method for transition state search. J Chem Phys, 2008, 128: 014106

93 Fonseca Guerra C, Snijders JG, te Velde G, et al. Towards an order-N DFT method. Theor Chem Acc, 1998, 99: 391-403

94 te Velde G, Bickelhaupt FM, Baerends EJ, et al. Chemistry with ADF. J Comput Chem, 2001, 22: 931-967

95 van Lenthe E, Baerends EJ. Optimized slater-type basis sets for the elements 1-118. J Comput Chem, 2003, 24: 1142-1156

96 van Lenthe E, Baerends EJ, Snijders JG. Relativistic regular twocomponent hamiltonians. J Chem Phys, 1993, 99: 4597-4610

97 van Lenthe E, Baerends EJ, Snijders JG. Relativistic total energy using regular approximations. J Chem Phys, 1994, 101: 97839792

98 Foster JP, Weinhold F. Natural hybrid orbitals. J Am Chem Soc, 1980, 102: 7211-7218

99 Reed AE, Weinhold F. Natural bond orbital analysis of NearHartree-Fock water dimer. J Chem Phys, 1983, 78: 4066-4073

100 Reed AE, Weinstock RB, Weinhold F. Natural population analysis. J Chem Phys, 1985, 83: 735-746

101 Krishnan R, Binkley JS, Seeger R, et al. Self-consistent molecular orbital methods. XX. A basis set for correlated wave functions. J Chem Phys, 1980, 72: 650-654

102 Hay PJ, Wadt WR. Ab initio effective core potentials for molecular calculations. Potentials for the transition metal atoms Sc to Hg. J Chem Phys, 1985, 82: 270-283

103 Hay PJ, Wadt WR. Ab initio effective core potentials for molecular calculations. Potentials for $\mathrm{K}$ to Au including the outermost core orbitals. J Chem Phys, 1985, 82: 299-310

104 Frisch MJ, Trucks GW, Schlegel HB, et al. Gaussian 09, Revision C01. Gaussian, Inc, Wallingford CT, 2010

105 Cao GJ, Schwarz WHE, Li J. An 18-electron system containing a 
superheavy element: Theoretical studies of $\mathrm{Sg} @ \mathrm{Au}_{12}$. Inorg Chem, 2015, 54: 3695-3701

106 Pyykkö P, Atsumi M. Molecular single-bond covalent radii for elements 1-118. Chem Eur J, 2009, 15: 186-197

Acknowledgements This work was supported by the National Natural Science Foundation of China (91645203, 21433005, and 21590792). The calculations were performed by using supercomputers at Tsinghua National Laboratory for Information Science and Technology and the Center for Computational Science and Engineering (SUSTech). The authors also acknowledge the Tsinghua Xuetang Talents Program for providing computational resources. Garzón IL thanks the support from DGAPA-UNAM (IN108817) and Conacyt-Mexico (285821).

Author contributions $\mathrm{Li} \mathrm{J}$ conceived the project. Baskaran $\mathrm{S}$ and $\mathrm{Xu}$ CQ carried out the theoretical calculations and co-wrote the paper. All authors discussed the results and commented on the manuscript.

Conflict of interest The authors declare that they have no conflict of interest.

Supplementary information Experimental details are available in the online version of the paper. Additional information on the optimized geometries, charges, bond lengths and bond orders of Au-Pd nanoparticle as well as the structures, adsorption energies and bonding analyses including the EDA and NBO analyses of $\mathrm{CO} @ \mathrm{Au}-\mathrm{Pd}$ and $\mathrm{O}_{2} @ \mathrm{Au}-\mathrm{Pd}$ is provided.

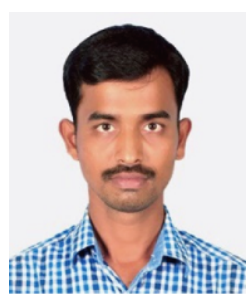

Sambath Baskaran received his $\mathrm{PhD}$ degree in 2015 from the Department of Chemistry, Pondicherry University and then started his postdoctoral research at Tsinghua University. He is now a postdoctoral fellow at Southern University of Science and Technology. His research interests focus on computational simulations of single atom catalysis.

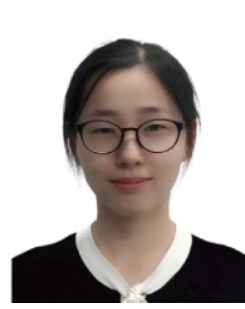

Cong-Qiao Xu received her $\mathrm{PhD}$ degree from the Department of Chemistry, Tsinghua University in 2017 and then became a postdoctoral fellow at Tsinghua University from 2017 to 2019. She is currently an assistant professor at the Department of Chemistry at Southern University of Science and Technology. Her research interests focus on theoretical inorganic chemistry and computational catalysis science.

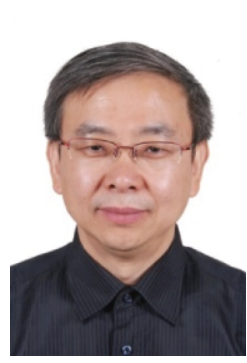

Jun Li received his $\mathrm{PhD}$ degree from Fujian Institute of Research on the Structure of Matter, Chinese Academy of Sciences in 1992. He did postdoctoral research at the University of Siegen and Ohio State University from 1994 to 1997 . He worked as a research scientist at Ohio State University and senior research scientist at the Pacific Northwest National Laboratory from 1997 to 2009 . He is now a full professor at Tsinghua University. His research involves theoretical chemistry, heavy-element chemistry, and computational catalysis science.

\section{Au-Pd单原子合金(SAA)催化剂的催化机理和成 键分析: CO氧化反应}

Sambath Baskaran ${ }^{1,2}$, 许聪俏 ${ }^{2^{*}}$, 王阳刚 ${ }^{2}$, Ignacio L. Garzón ${ }^{3}$, 李隽 $1,2^{*}$

摘要 单原子催化剂(SACs)在催化科学领域引起了人们的广泛关 注, 包括被称为单原子合金 (SAAs)的包含金属-金属键合的双金属 催化剂. 本文通过量子化学计算方法研究了 $\mathrm{Au}-\mathrm{Pd}$ 单原子合金模 型 $\mathrm{Au}_{37} \mathrm{Pd}_{1}$ 上 $\mathrm{CO}$ 氧化反应的催化机理和成键分析, 确定了 $\mathrm{CO} @ \mathrm{Au}-\mathrm{Pd}, \mathrm{O}_{2} @ \mathrm{Au}-\mathrm{Pd}$ 和CO/O $\mathrm{O}_{2} @ \mathrm{Au}-\mathrm{Pd}$ 等吸附构型的几何结构 以及吸附物与底物间的结合能. Pd原子位于核芯位置的核-壳结构 被证实为 $\mathrm{Au}-\mathrm{Pd}$ 单原子合金的最稳定构型, 该结构的稳定性来源 于 $\mathrm{Pd}$ 原子向 $\mathrm{Au}$ 原子的电荷转移. 根据结合能和化学成键分析, $\mathrm{CO}$ 和 $\mathrm{O}_{2}$ 分子均优先吸附在配位数低且位于顶点位置的 $\mathrm{Pd}$ 原子上. 本 文报道了一种新的 $\mathrm{CO}$ 和 $\mathrm{O}_{2}$ 共吸附结构, 其中 $\mathrm{CO}$ 和 $\mathrm{O}_{2}$ 分别在两个 相邻 $\mathrm{Au}-\mathrm{Pd}$ 键上以垂直和平行桥联方式吸附, 该 $\mathrm{Au}-\mathrm{Pd}$ 单原子合金 的 $\mathrm{CO}$ 氧化反应具有低能垒且遵循Langmuir-Hinshewood (L-H) 机 理. 本文探讨了单原子合金催化剂中单原子在催化反应中的重要 作用，可以为设计具有优异催化活性的新型单原子合金催化剂提 供依据. 